\title{
The Volatility Spillover Effect Between the International Crude Oil Futures Price and China's Stock Market - Multivariate BEKK-GARCH Model Based on Wavelet Multiresolution
}

\author{
Maoguo $\mathrm{Wu}^{1} \&$ Zhehao $\mathrm{Zhu}^{1}$ \\ ${ }^{1}$ SHU-UTS SILC Business School, Shanghai University, Shanghai, China \\ Correspondence: Zhehao Zhu, SHU-UTS SILC Business School, Shanghai University, 20 Chengzhong Road, Jiading \\ District, Shanghai 201899, China.
}

Received: May 30, 2019

Accepted: July 4, 2019

Online Published: July 16, 2019

doi:10.5430/ijfr.v10n4p84

URL: https://doi.org/10.5430/ijfr.v10n4p84

\begin{abstract}
This study aims to analyze the volatility spillover effect between the international crude oil futures market and China's stock market. Using West Texas Intermediate (WTI) and the Shanghai Composite Index (SSEC) to represent the international crude oil futures market and China's stock market respectively, this study selects data of WTI and the SSEC from August 10, 2007 to August 10, 2017. It processes these data via wavelet multiresolution to decompose them into different levels and then builds the data model based on the BEKK-GARCH model. By testing the parameters through the Wald test, it further explores whether the volatility spillover effect exists between WTI and the SSEC. Empirical evidence finds that the volatility spillover effect between WTI and the SSEC is significant in the short run, while, however, such a volatility spillover effect does not exist in the medium and long term.
\end{abstract}

Keywords: wavelet multiresolution, BEKK-GARCH model, volatility spillover effect, WTI, Shanghai composite index

\section{Introduction}

In 1859, the first modern industrial crude oil well was drilled in the U.S.A., since which the crude oil industry has developed over the last 160 years. With increasingly advanced technology for crude oil exploitation and utilization, crude oil is playing an indispensable role as it is widely used in industrial production and these products have already become necessities of daily life. As a non-renewable resource, in addition, crude oil will continue to reshape the global economic pattern because competition for crude oil resources among countries would not cease before the emergence of another resource that could substitute for crude oil perfectly. Therefore, if a crude oil crisis occurs, it would strike the national economy of many countries. The first crude oil crisis in 1973 caused the U.S. economy to shrink by almost $30 \%$, with its unemployment rate increasing from $4.9 \%$ to $8.5 \%$ and its inflation rate increasing from $3.4 \%$ to $12.2 \%$. In the 1980 s, the second crude oil crisis also slowed down the national economy of United Kingdom and United States. The GDP of United Kingdom and United States then decreased by 2.4\% and 0.2\%, respectively.

Despite the shocks to the economy of foreign countries, China was almost immune to these crude oil crises as it used to have a less open economy. However, China's current economy is more closely connected to the global economy, as China now imports 461,905 barrels of crude oil a year. As such, China's economy is sensitive to movements in the crude oil market; hence, the relation between the crude oil futures market and China's stock market deserves special attention.

In order to mitigate the risks resulting from the fluctuation of the crude oil price, the crude oil futures market has emerged with its function of price discovery, risk diversification and speculation standardization, among which the West Texas Intermediate (WTI) has the largest trading volume of crude oil futures. WTI, actually the futures contract of light sweet crude with large transaction volume and high price transparency and liquidity, is regarded as the basic crude oil price of all crude oil transported to or sold in the U.S.A.

This study selects the data of WTI and the Shanghai Composite Index (SSEC) from August 10, 2007 to August 10, 2017 to explore the volatility spillover effect between the international crude oil futures market and China's stock market. It then processes the data through wavelet multiresolution and builds the model on the basis of the 
BEKK-GARCH model. Furthermore, this study utilizes the Wald test to investigate whether the volatility spillover effect exists.

The remaining part of this study is organized as follows: Section 2 reviews related literature; Section 3 introduces the data; Section 4 is devoted to empirical analysis; Section 5 then concludes the study.

\section{Related Literature}

Previous literature generally states that the crude oil futures price and the stock market influence each other because the crude oil price and the macroeconomy are closely connected. Huang, Masulis and Stoll (1996) find that the discount rate and the future cash flows of enterprises change according to the fluctuation of the crude oil futures price and the expected discount rate is determined by the interest rate, the market capital and the expected inflation rate. Fried and Schultze (1975) point out that the increase in crude oil price would decrease the overall demand of the global economy, which, in turn, would result in economic depression. Likewise, Rasch and Tatom (1977) employ a system that is similar to the real macroeconomy with six variables and confirm that the increase in crude oil price would slow down the economy. They argue that although crude oil exploitation and processing enterprises are most vulnerable to the rising crude oil price, almost all enterprises would be affected by the fluctuation of the crude oil price as they all apply crude oil as fuel or raw materials in some manner. Hence, it is concluded that the fluctuation of the crude oil price has great impact on the operation of many enterprises and thus affects their cash flows.

Moreover, when cash flows and profits of most of the enterprises in an economy are affected, such fluctuations would be reflected in stock prices, which would subsequently lead to shocks to the stock market. Chen, Roll and Ross (1986) utilize the multifactor model to study the impact of the crude oil price on the stock market, which sets an example for the early studies. Thereafter, Hamao (1989), Ferson and Havey (1995) also adopt the multifactor model to analyze the relation between the crude oil price and the stock market. Nevertheless, not only Chen, Roll and Ross's (1986) research on the U.S. stock market, but also Hamao's (1989) study on Japan's stock market fail to observe a significant impact of the crude oil price on the stock market. Moreover, Huang, Masulis and Stoll (1996) could not find evidence to verify that the change of the crude oil price is negatively correlated with the stock market return. Ferson and Havey (1995) argue that impact of the risk factor of the crude oil price varies among countries: mature stock markets of developed countries are closely related to the crude oil price, while emerging markets of developing countries are less influenced by the crude oil price. Jones and Kaul (1996), additionally, observe that the impact of the crude oil price on Japan's stock market and Britain's stock market is not significant, but the impact on Canada's stock market and the U.S. stock market is significant, which, they conclude, may result from different crude oil reserves and import demands among countries. Based on the VAR model, Sadorsky (1999) finds that the shock induced by the crude oil price on the effective rate of return of the stock market is significant and unsymmetrical.

In recent years, there have been more studies analyzing China's stock market and the international crude oil futures market. Lao (2007) utilizes the multifactor regression to explore the relation between SSEC and the international crude oil futures price. The study found that the international crude oil futures price positively affects the SSEC, which, according to Lao (2007), is possibly because China's stock market was immature at that time and was therefore not strongly connected to the international financial market. Through the unsymmetrical BEKK model and the Wald test, Zhu (2015) finds that there is a two-way spillover effect between the crude oil futures market and the stock market.

\section{Data}

This study gathers 2,561 observations from trading days of WTI and the SSEC that match each other from August 10, 2007 to August 10, 2017. The data of WTI are collected from the website of the U.S. National Energy Agency and the data of the SSEC are collected from the website of Investing.com. In order to avoid spurious regression, this study uses the rate of return for the original sequence:

$$
R_{i, t}=100 \times \ln \left(P_{i, t} / P_{i, t-1}\right)
$$

In the above equation, $\mathrm{R}$ represents the rate of return sequence, $\mathrm{t}$ represents the $\mathrm{t}^{\text {th }}$ trading day and $\mathrm{P}$ represents the closing price. When i takes the value of 1 , it represents the sequence of rate of return and price of the SSEC; when $i$ takes the value of 2, it represents the sequence of rate of return and price of WTI. Based on the sequence of rate of return and the sequence after wavelet multiresolution, the basic statistics are summarized in Table 1. In Table 1, the $\mathrm{J}$-B value of each sequence is relatively large and the kurtosis value of each is all above 3.7, which indicates that these sequences do not follow normal distribution and they show leptokurtosis and fat-tail. From Q (5) and Q (10), the results of autoregression are all significant at the $1 \%$ level, which implies that both the original sequence and the 
sequence after wavelet multiresolution have autoregression. In Q2 (5) and Q2 (10), the results of the ARCH test are all significant at the $1 \%$ level. This study then utilizes the ADF stationarity test and finds that each sequence is stationary, so it could further build the model.

Table 1. Basic statistics of the original sequence of WTI and SSEC and the sequence after wavelet multiresolution

\begin{tabular}{|c|c|c|c|c|c|c|c|c|c|c|c|c|}
\hline & SSEC & & & & & & WTI & & & & & \\
\hline & $\mathrm{S}$ & A4 & D1 & D2 & D3 & D4 & $\mathrm{S}$ & A4 & D1 & D2 & D3 & D4 \\
\hline Mean & $6.49 \mathrm{e}-05$ & $7.17 \mathrm{e}-05$ & 0.0000 & 0.0000 & $-1.26 \mathrm{e}-20$ & $1.28 \mathrm{e}-21$ & 0.000178 & 0.0002 & 0.0000 & $5.51 \mathrm{e}-07$ & $-3.97 \mathrm{e}-06$ & $-1.48 \mathrm{e}-06$ \\
\hline Standard & 0.0170 & 0.0046 & 0.0118 & 0.0085 & 0.00616 & 0.00410 & 0.025073 & 0.0060 & 0.01832 & 0.01219 & 0.009073 & 0.005200 \\
\hline $\mathrm{J}$-B value & 1736.2 & 220.605 & 895.95 & 1839.46 & 1152.202 & 103.953 & 2579.204 & 526.90 & 3975.22 & 1007.94 & 2373.908 & 52.78139 \\
\hline Kurtosis & 7.0494 & 4.11473 & 5.9625 & 7.24490 & 6.359594 & 4.00912 & 7.940173 & 5.1978 & 9.24027 & 6.14224 & 7.822303 & 3.719005 \\
\hline Q (5) & $15.124^{* * *}$ & $8467 . * * *$ & $574.7^{* * *}$ & $1088^{* * *}$ & $2129 . * * *$ & $3043 . * * *$ & $31.58^{* * *}$ & $8384 . * * *$ & $578.2^{* * *}$ & $898.8^{* * *}$ & $2012.6^{* * *}$ & $3250.0^{* * *}$ \\
\hline Q（10） & $24.67^{* * *}$ & $12115^{* * * *}$ & $588.3 * * *$ & $1143 . * * *$ & $2309 . * * *$ & $5150 . * * *$ & $35.09 * * *$ & $11874^{* * *}$ & $583.4 * * *$ & $906.9^{* * * *}$ & $2334.6^{* * *}$ & $4878.3^{* * *}$ \\
\hline Q2（5) & $91.006 * * *$ & $1548.31^{* * *}$ & $911.731^{* * *}$ & $1572.63^{* *}$ & $1454.1^{* * *}$ & $2224.0^{* * *}$ & $133.41^{* * *}$ & $1573.7^{* * *}$ & $924.332^{* *}$ & $1627.23^{* * *}$ & $1338.4^{* * *}$ & $2170.1^{* * *}$ \\
\hline Q2（10） & $89.801^{* * *}$ & $2049.356^{* * *}$ & $909.323^{* * *}$ & $1549.00^{* *}$ & $1909.1^{* * *}$ & $1647.4^{* * *}$ & $140.87 * * *$ & $2067.6^{* * *}$ & $928.159^{* *}$ & $1620.81^{* * *}$ & $2136.31^{* * *}$ & $1854.10^{* * *}$ \\
\hline ADF & $-48.254^{* * *}$ & $-7.12279 * * *$ & $-20.922^{* * *}$ & $-15.738^{* * *}$ & $-13.224^{* * *}$ & $-11.30^{* * *}$ & $-52.451^{* * *}$ & $-6.2009 * * *$ & $-20.038^{* * *}$ & $-17.545^{* * *}$ & $-15.455^{* * *}$ & $-12.438^{* * *}$ \\
\hline Conclusion & Stationary & Stationary & Stationary & Stationary & Stationary & Stationary & Stationary & Stationary & Stationary & Stationary & Stationary & Stationary \\
\hline
\end{tabular}

\section{Empirical Analysis}

This study utilizes Eviews 8 to analyze the basic statistics, applies MATLAB2016a for wavelet multiresolution and utilizes WINRATS 8 to build the BEKK-GARCH model and adopt the Wald test. The parameter estimation of the BEKK-GARCH model is shown in Table 2 and the results of the Wald test are shown in Table 3.

From the results of the Wald test, the original sequence of S has a two-way volatility spillover effect: the volatility of WTI would be transmitted to the SSEC quickly and, similarly, the volatility of the SSEC would be transmitted to WTI immediately. According to the value of $\alpha 12, \alpha 21, \beta 12$ and $\beta 21$ of the BEKK-GARCH model and its significance level, the coefficients of the volatility spillover effect of WTI on the SSEC and the volatility spillover effect of the SSEC on WTI are negative, significantly at the 5\% level. As crude oil has developed for a long time and has become the raw material of many pillar industries, the price of international crude oil futures could reflect the conditions of the macroeconomy. To that extent, the increase in the price of WTI- which represents the price of international crude oil futures- would lead to shocks to many industries that use crude oil as the raw material and thus affect profits of enterprises. If the profit of a listed company decreases, the listed company would be affected negatively and, as a result, its stock price would also go down. As such, the SSEC index would drop, since the number of companies that use crude oil as a raw material (and thereby would be affected by crude oil price) is large. Furthermore, to ensure their profits, companies are likely to force consumers to pay for the rising crude oil price by increasing the prices of their products, which, in turn, would inflate prices. In addition, the rising price level would result in rising inflation and then slow down the macroeconomy. Because of the weak macroeconomy, investors would lose confidence in the stock market and withdraw their money, which would cause the stock prices and the stock index to drop even more. In contrast, if the stock index is rising, investors would become confident in the stock market and would therefore invest more money in the stock market to earn more returns. WTI, a futures market, has the characteristics of the financial market, which indicates that its price would be affected by the amount of funds available. If the total amount of funds is fixed, the WTI market would share the funds with the stock market, meaning that if more funds are invested in the stock market, there would be less funds in the WTI market, which would thus decrease its price. Since the original data may contain irregular factors and noises, this study builds the model and analyzes the data once more after adopting wavelet multiresolution so as to precisely examine the volatility spillover effect between WTI and the SSEC. After wavelet multiresolution, data could be analyzed in the short term, the medium term and the long term. The D1 level and D2 level are high-frequency data, which could be used to explore the short-term volatility spillover effect. In Table 2 and Table 3, both the two-way and one-way volatility spillover effect of WTI and the SSEC are significant, implying that the two markets both respond with fast speed and in a short period as the volatility in one market would be immediately transmitted to the other. Since WTI represents the international crude oil futures price, the short-term volatility spillover effect between WTI and the SSEC indicates that the SSEC is a highly international index as it is sensitive to fluctuation in the international crude oil futures market. Moreover, the reason why the short-term volatility spillover effect is significant may be that China has not yet finished the transition of its economic mainstay from secondary industries to tertiary industries. Secondary industries being its current economic mainstay, China relies heavily on and is a massive importer of crude 
oil, which could explain why China's market is very much related to the crude oil futures price.

The D3 level and D4 level represent the time scale of eight days and sixteen days respectively, which could be applied to study the medium-term volatility spillover effect. The A4 level represents the low-frequency data that could be utilized to explore the long-run effects and trends. Through the BEKK-GARCH model and the Wald test, it was found that neither the two-way volatility spillover effect nor the one-way volatility spillover effect is significant. Likewise, the test result of A4 also suggests that there is no significant volatility spillover effect. Since the original sequence shows a significant volatility spillover effect, this study infers that in the medium and long term, the volatility spillover effect represents the lagging effect of markets to some extent.

Table 2. BEKK-GARCH parameter estimation

\begin{tabular}{|c|c|c|c|c|c|c|}
\hline & $\mathrm{S}$ & D1 & D2 & D3 & D4 & A4 \\
\hline $\mathrm{A}_{11}$ & $\begin{array}{l}0.2707 * * * \\
(12.128)\end{array}$ & $\begin{array}{l}-0.0254 \\
(-1.0337)\end{array}$ & $\begin{array}{l}0.1198 * * * \\
(8.3555)\end{array}$ & $\begin{array}{l}0.3000 * * * \\
(13.904)\end{array}$ & $\begin{array}{l}0.6433 * * * \\
(30.705)\end{array}$ & $\begin{array}{l}0.8863 * * * \\
(55.823)\end{array}$ \\
\hline $\mathrm{A}_{21}$ & $\begin{array}{l}0.0122 * * * \\
(6.5848)\end{array}$ & $\begin{array}{l}0.0236 * * * \\
(12.371)\end{array}$ & $\begin{array}{l}0.004 \\
(0.6706)\end{array}$ & $\begin{array}{l}0.0113 * \\
(1.9594)\end{array}$ & $\begin{array}{l}0.0017 \\
(0.2117)\end{array}$ & $\begin{array}{l}-0.0048 \\
(-0.3782)\end{array}$ \\
\hline $\mathrm{C}_{1}$ & $\begin{array}{l}-0.002 * * * \\
(-4.6247)\end{array}$ & $\begin{array}{l}0.0002 \\
(0.4712)\end{array}$ & $\begin{array}{l}0.0001 \\
(0.9555)\end{array}$ & $\begin{array}{l}0.0001 * \\
(0.0041)\end{array}$ & $\begin{array}{l}0.0001 \\
(1.0484)\end{array}$ & $\begin{array}{l}0.0001 \\
(0.2351)\end{array}$ \\
\hline $\mathrm{A}_{12}$ & $\begin{array}{l}12.786 * * * \\
(13.669)\end{array}$ & $\begin{array}{l}26.504 * * * \\
(8.7175)\end{array}$ & $\begin{array}{l}-0.0277 * * \\
(-2.088)\end{array}$ & $\begin{array}{l}0.0153 \\
(1.0751)\end{array}$ & $\begin{array}{l}0.0056 \\
(0.5061)\end{array}$ & $\begin{array}{l}-0.0082 \\
(-0.5809)\end{array}$ \\
\hline $\mathrm{A}_{22}$ & $\begin{array}{l}-0.1131 * * * \\
(0.0188)\end{array}$ & $\begin{array}{l}-1.1560 * * * \\
(-8.4582)\end{array}$ & $\begin{array}{l}0.0992 * * * \\
(7.6328)\end{array}$ & $\begin{array}{l}0.3617 * * * \\
(6.5926)\end{array}$ & $\begin{array}{l}0.6479 * * * \\
(29.384)\end{array}$ & $\begin{array}{l}0.8808 * * * \\
(62.490)\end{array}$ \\
\hline $\mathrm{C}_{2}$ & $\begin{array}{l}-0.1228 * * * \\
(-6.014)\end{array}$ & $\begin{array}{l}0.0206 * * * \\
(9.1506)\end{array}$ & $\begin{array}{l}-0.0001 \\
(-0.725)\end{array}$ & $\begin{array}{l}-0.0001 \\
(-0.9683)\end{array}$ & $\begin{array}{l}0.0001 \\
(1.0520)\end{array}$ & $\begin{array}{l}0.0001 \\
(0.9723)\end{array}$ \\
\hline$\Theta_{1}$ & $\begin{array}{l}0.5515^{* *} \\
(2.0241)\end{array}$ & $\begin{array}{l}0.5763 * * * \\
(3.9462)\end{array}$ & $\begin{array}{l}0.0033 * * * \\
(7.0860)\end{array}$ & $\begin{array}{l}0.0018 * * * \\
(6.3368)\end{array}$ & $\begin{array}{l}0.0010 * * * \\
(24.114)\end{array}$ & $\begin{array}{l}0.0011 * * * \\
(10.810)\end{array}$ \\
\hline$\Theta_{2}$ & $\begin{array}{l}33.964 * * \\
(2.0440)\end{array}$ & $\begin{array}{l}35.369 * * * \\
(3.9521)\end{array}$ & $\begin{array}{l}0.0001 \\
(0.1441)\end{array}$ & $\begin{array}{l}0.0003 \\
(1.4150)\end{array}$ & $\begin{array}{l}-0.0001 \\
(-0.3658)\end{array}$ & $\begin{array}{l}0.0001 \\
(0.3843)\end{array}$ \\
\hline$\Theta_{3}$ & $\begin{array}{l}-0.1326^{*} \\
(-1.861)\end{array}$ & $\begin{array}{l}-0.06625 * * * \\
(-3.1494)\end{array}$ & $\begin{array}{l}0.0033 * * * \\
(7.7351)\end{array}$ & $\begin{array}{l}0.0014 \\
(1.4694)\end{array}$ & $\begin{array}{l}0.0013 * * * \\
(10.374)\end{array}$ & $\begin{array}{l}0.0013 * * * \\
(8.3710)\end{array}$ \\
\hline$\alpha_{11}$ & $\begin{array}{l}0.3870 * * * \\
(28.509)\end{array}$ & $\begin{array}{l}0.0921 * * * \\
(5.8846)\end{array}$ & $\begin{array}{l}0.9368 * * * \\
(35.519)\end{array}$ & $\begin{array}{l}0.9155 * * * \\
(11.475)\end{array}$ & $\begin{array}{l}1.4632 * * * \\
(20.785)\end{array}$ & $\begin{array}{l}1.7187 * * * \\
(9.7484)\end{array}$ \\
\hline$\alpha_{12}$ & $\begin{array}{l}-4.023 * * \\
(-2.255)\end{array}$ & $\begin{array}{l}12.776 * * * \\
(17.371)\end{array}$ & $\begin{array}{l}0.0199 \\
(0.9779)\end{array}$ & $\begin{array}{l}0.0127 \\
(0.4360)\end{array}$ & $\begin{array}{l}-0.0360 \\
(-0.7804)\end{array}$ & $\begin{array}{l}0.0536 \\
(0.5061)\end{array}$ \\
\hline$\alpha_{21}$ & $\begin{array}{l}-0.0069 * * * \\
(-6.541)\end{array}$ & $\begin{array}{l}-0.0059 * * * \\
(-11.807)\end{array}$ & $\begin{array}{l}-0.0085 \\
(-0.927)\end{array}$ & $\begin{array}{l}-0.0109 \\
(-0.6969)\end{array}$ & $\begin{array}{l}-0.0094 \\
(-0.4145)\end{array}$ & $\begin{array}{l}0.0576 \\
(0.6712)\end{array}$ \\
\hline$\alpha_{22}$ & $\begin{array}{l}0.7941 * * * \\
(9.0428)\end{array}$ & $\begin{array}{l}0.6524 * * * \\
(20.585)\end{array}$ & $\begin{array}{l}0.9645 * * * \\
(36.284)\end{array}$ & $\begin{array}{l}0.6521 * * * \\
(3.9594)\end{array}$ & $\begin{array}{l}1.4420 * * * \\
(21.196)\end{array}$ & $\begin{array}{l}1.8502 * * * \\
(10.107)\end{array}$ \\
\hline$\beta_{11}$ & $\begin{array}{l}0.8591 * * * \\
(844.60)\end{array}$ & $\begin{array}{l}0.8571 * * * \\
(2147 .)\end{array}$ & $\begin{array}{l}-0.0408 \\
(-0.960)\end{array}$ & $\begin{array}{l}0.3288 * * \\
(2.1880)\end{array}$ & $\begin{array}{l}0.0001 \\
(1.48 \mathrm{e}-004)\end{array}$ & $\begin{array}{l}0.0001 \\
(1.26 \mathrm{e}-005)\end{array}$ \\
\hline$\beta_{12}$ & $\begin{array}{l}-0.2745 * * * \\
(-7.5721)\end{array}$ & $\begin{array}{l}-0.7951 * * * \\
(-11.090)\end{array}$ & $\begin{array}{l}0.4252 * * * \\
(7.5559)\end{array}$ & $\begin{array}{l}-0.0389 \\
(-0.7139)\end{array}$ & $\begin{array}{l}-0.0001 \\
(-1.17 \mathrm{e}-004)\end{array}$ & $\begin{array}{l}-0.0001 \\
(-3.70 \mathrm{e}-005)\end{array}$ \\
\hline$\beta_{21}$ & $\begin{array}{l}-0.0001 * * \\
(-2.388)\end{array}$ & $\begin{array}{l}-0.0003 * * * \\
(-9.0392)\end{array}$ & $\begin{array}{l}-0.1242 * * * \\
(-3.941)\end{array}$ & $\begin{array}{l}0.0018 \\
(0.0765)\end{array}$ & $\begin{array}{l}-0.0001 \\
(-1.09 \mathrm{e}-004)\end{array}$ & $\begin{array}{l}-0.0001 \\
(-2.9 \mathrm{e}-005)\end{array}$ \\
\hline$\beta_{22}$ & $\begin{array}{l}0.8599 * * * \\
(1006.3)\end{array}$ & $\begin{array}{l}0.8523 * * * \\
(668.82)\end{array}$ & $\begin{array}{l}-0.0521 \\
(-1.575)\end{array}$ & $\begin{array}{l}0.7661 * * * \\
(4.4723)\end{array}$ & $\begin{array}{l}0.0001 \\
(1.20 \mathrm{e}-004)\end{array}$ & $\begin{array}{l}-0.0001 \\
(-2.65 \mathrm{e}-005)\end{array}$ \\
\hline
\end{tabular}


Table 3. The Wald test

\begin{tabular}{lllllll}
\hline $\begin{array}{l}\text { Null } \\
\text { hypothesis }\end{array}$ & $\begin{array}{l}\text { The two-way volatility } \\
\text { spillover effect between WTI } \\
\text { and SSEC does not exist. } \\
H_{0}: \alpha_{12}=\alpha_{21}=\beta_{12}=\beta_{21}=0\end{array}$ & $\begin{array}{l}\text { The one-way volatility spillover } \\
\text { effect of SSEC on WTI does not } \\
\text { exist. }\end{array}$ & $\begin{array}{l}\text { The one-way volatility spillover } \\
H_{0}: \alpha_{12}=\beta_{12}=0\end{array}$ & $\begin{array}{l}\text { sfect of WTI on SSEC does not } \\
\text { exist. }\end{array}$ \\
\hline & F value & Significance level & F value & Significance level & F value & Significance level \\
\hline S & 2605.9835 & 0.0000 & 1469.1043 & 0.000 & 4033.5665 & 0.0000 \\
\hline D1 & 6821.6992 & 0.0000 & 1224.4047 & 0.0000 & 1006.50792 & 0.0000 \\
\hline D2 & 27.7978 & 0.0000 & 1.0431 & 0.3523 & 55.06651 & 0.0000 \\
\hline D3 & 0.8782 & 0.4759 & 0.5258 & 0.5910 & 0.2567 & 0.7736 \\
\hline D4 & 0.2450 & 0.9128 & 0.3120 & 0.7319 & $7.42 \mathrm{e}-009$ & 0.9999 \\
\hline A4 & 0.2575 & 0.9051 & 0.2980 & 0.7422 & $6.91 \mathrm{e}-010$ & 1.0000 \\
\hline
\end{tabular}

As international financial markets are closely related to each other, when a shock occurs in the crude oil futures market, it will be immediately transmitted to the stock market. This means that WTI and the SSEC are both so sensitive to each other that they could respond to the fluctuation in the respective other market in a very short time. Therefore, the medium-term and long-term volatility spillover effects are not significant because there is no lag period.

\section{Conclusion}

Collecting the data of WTI and the SSEC from August 10, 2007 to August 10, 2017, this study separates the data into low-frequency data and high-frequency data through wavelet multiresolution. After analyzing the basic statistics of all sequences, this study, on the basis of the BEKK-GARCH model, investigates whether the volatility spillover effect between WTI and the SSEC is significant at different data levels. Empirical evidence shows that in the original sequence and the D1 and D2 levels, the two-way volatility spillover effect between WTI and the SSEC is significant; in the D3, D4 and A4 levels, the volatility spillover effect between WTI and the SSEC is not significant. This study reaches the following conclusions.

1) The volatility spillover effect between WTI and the SSEC is significant in the short term. With the increasing economic and trading volume, China now has a financial market that is more closely related to the international financial market. Such strong linkage means a fast reaction speed and a short reaction period, which makes China's market more sensitive to the fluctuation in the international market. The stronger relation between China's financial market and the international market indicates China's increasing importance in the world. However, this would also aggravate a financial crisis and involve more markets when the international market encounters systematic risk.

2) The volatility spillover effect between WTI and the SSEC is not significant in the medium and long term. When the stock market is sensitive to a certain level, the transmission of the shock from one market to another is immediate with no lagging effect, so the medium-term and the long-term volatility spillover effects are not significant.

3) In China, the transmission of economic mainstay from secondary industries to tertiary industries has not been completed yet. The volatility spillover effect of the original sequence indicates that China's stock market is sensitive to the crude oil futures market. It may be because most listed companies in China are from secondary industries and they use crude oil as the raw material; hence, their profits would be affected greatly by the fluctuation of crude oil price. As such, China's government should accelerate the process of transferring the economic mainstay from secondary industries to tertiary industries, because secondary industries are for the most part industries with high pollution and high energy consumption.

\section{References}

Chen, Y., \& Chen, Q. (2007). Asymmetric stage effects on the international crude oil price shocks and Chinese macroeconomic activities: 1978-2007. Financial Research, 5, 86-99.

Filis, G. (2010). Macroeconomy, Stock Market and Crude Oil Prices: Do Meaningful Correlations Exist in Cyclical Fluctuations?. Energy Economics, 32(4), 877-886. https://doi.org/10.1016/j.eneco.2010.03.010 
Finn, M. G. (1999). An Equilibrium Theory of Nominal and Real Exchange Rate Comovement. Journal of Monetary Economics, 44(3), 453-475. https://doi.org/10.1016/S0304-3932(99)00034-3

Hooker, M. A. (1996). What Happened to the Crude Oil Price-Macroeconomy Relationship?. Journal of Monetary Economics, 38(2), 195-213. https://doi.org/10.1016/S0304-3932(96)01281-0

Jin, H., \& Jin, L. (2008). Spillover effects with correlation between the crude oil price and the stock market Evidence based on data from China and U.S. Financial Research, 2, 83-97.

Jin, H., \& Jin, L. (2010). Impact of international crude oil price on China's stock market - Evidence from industry data. Financial Research, 2, 173-187.

Kaul, G., \& Seyhun, H. N. (1990). Relative Price Variability, Real Shocks, and the Stock Market. The Journal of Finance, 45(2), 479-496. https://doi.org/10.1111/j.1540-6261.1990.tb03699.x

Lao, J. (2008). Does the crude oil price have impact on the Shanghai Composite Index? - Empirical evidence based on data from 2000 to 2007. World Economic Condition, 5, 71-77.

Maghyereh, A. (2006). Crude Oil Price Shocks and Emerging Stock Markets: A Generalized VAR Approach. Palgrave Macmillan UK, l(2), 27-40. https://doi.org/10.1057/9780230599338_5

Mao, J. (2003). The strategic position and security of crude oil resource. Sinopec, 5, 86-99.

Zeng, H. (2012). Empirical research on the relationship between the international crude oil price and China's stock market. Southwestern University of Finance and Economics, 1-70.

Zhu, H., \& Zhang, Y. (2005). Analysis of the relationship between money supply and inflation based on the ECM model. Management Science, 18(5), 51-56. 